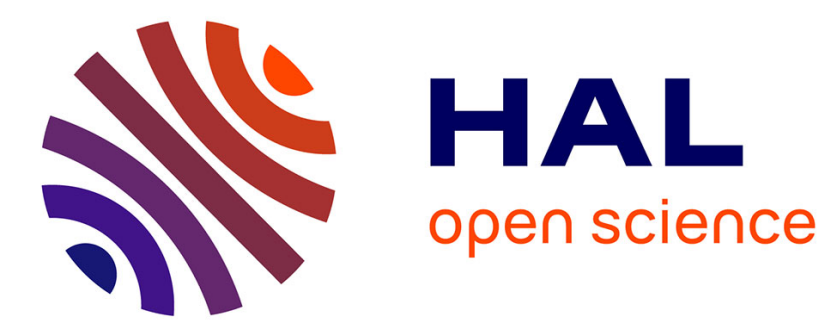

\title{
Electroanalysis at a single giant vesicle generating enzymatically a reactive oxygen species
}

\author{
Pauline Lefrançois, Jérôme Santolini, Stéphane Arbault
}

\section{To cite this version:}

Pauline Lefrançois, Jérôme Santolini, Stéphane Arbault. Electroanalysis at a single giant vesicle generating enzymatically a reactive oxygen species. Analytical Chemistry, 2021, 93 (39), pp.1314313151. 10.1021/acs.analchem.1c01208 . hal-03424345

\section{HAL Id: hal-03424345 \\ https://hal.science/hal-03424345}

Submitted on 10 Nov 2021

HAL is a multi-disciplinary open access archive for the deposit and dissemination of scientific research documents, whether they are published or not. The documents may come from teaching and research institutions in France or abroad, or from public or private research centers.
L'archive ouverte pluridisciplinaire HAL, est destinée au dépôt et à la diffusion de documents scientifiques de niveau recherche, publiés ou non, émanant des établissements d'enseignement et de recherche français ou étrangers, des laboratoires publics ou privés. 


\title{
Electroanalysis at a single giant vesicle generating enzymatically a reactive oxygen species
}

\author{
Pauline Lefrançois, ${ }^{a}$ Jérôme Santolini ${ }^{b}$ and Stéphane Arbault*a,c \\ a Univ. Bordeaux, CNRS, Bordeaux INP, ISM, UMR 5255 CNRS, F-33400 Talence, France \\ ${ }^{b}$ Institute for Integrative Biology of the Cell (I2BC), CEA, CNRS, Univ. Paris-Sud, Univ. Paris-Saclay, F-91198 Gif-sur-Yvette \\ Cedex, France. \\ c. Univ. Bordeaux, CNRS, Bordeaux INP, CBMN, UMR 5248 CNRS, F-33600 Pessac, France. \\ *Corresponding author : Dr Stéphane Arbault ; stephane.arbault@u-bordeaux.fr ; Tel : +330540006851.
}

\begin{abstract}
In the framework of artificial or synthetic cell development, giant liposomes are common basic structures. Their enclosed membrane permits to encapsulate proteins, DNA, reactants, etc while its phospholipid nature allows some exchanges with the surrounding medium. Biochemical reactions induced inside giant liposomes or vesicles are often monitored or imaged by fluorescence microscopy techniques. Here, we show that electrochemistry performed with ultramicroelectrodes is perfectly suitable to monitor an enzymatic reaction occurring in a single giant unilamellar vesicle. Glucose oxidase (GOx) was micro-injected inside individual vesicles containing $1 \mathrm{mM}$ glucose. $\mathrm{H}_{2} \mathrm{O}_{2}$ was thus generated in the vesicle and progressively diffused across the membrane toward the surrounding environment. An ultramicroelectrode sensitive to $\mathrm{H}_{2} \mathrm{O}_{2}$ (black platinum-modified carbon surface) was placed next to the membrane and provided a direct detection of the hydrogen peroxide flux generated by the enzyme activity. Electrochemistry offered a highly sensitive (in situ detection), selective (potential applied at the electrode), time-resolved analysis (chronoamperometry) of the GOx activity over an hour duration, without modifying the internal GUV medium. These results demonstrate that electroanalysis with microsensors is well adapted and complementary to fluorescence microscopy to sense enzymatic activities, for instance generating Reactive Oxygen Species, at single vesicles further used to develop artificial cells.
\end{abstract}

\section{INTRODUCTION}

Enzymatic reactions are ubiquitously involved in physiological and pathological processes in living organisms. These reactions often lead to the production of several products including unstable-reactive species. Among those, the reactive oxygen and nitrogen species (ROS and RNS), which include at least superoxide $\left(\mathrm{O}_{2}{ }^{\circ}\right)$, hydroxyl $\left(\mathrm{HO} \mathrm{O}^{*}\right)$, nitric oxide $\left(\mathrm{NO}^{\circ}\right)$, nitrogen dioxide radicals $\left(\mathrm{NO}_{2}{ }^{\circ}\right)$, peroxynitrite anion (ONOO-), hydrogen peroxide $\left(\mathrm{H}_{2} \mathrm{O}_{2}\right)$ etc., are of great interest as they play multiple biological role ${ }^{1-2}$. On the one hand, ROS and RNS provide chemical means to mammalian immune cells or plant cells to inactivate foreign entities (bacteria, fungi, viruses, particles, etc. $)^{3-5}$; some also trigger redox signaling pathways including the iron-nitrosylation by $\mathrm{NO}^{\circ}$ in the guanylate cyclase activation ${ }^{3-5}$. On the other hand, ROS and RNS cause oxidative and nitrosative damages to biological macromolecules (proteins, lipids, DNA, etc.) ensuing dysfunctions in all types of tissues and pathological issues for organisms. ${ }^{2,6-7}$

The high reactivity of ROS and RNS induces their short lifetimes (ns-min) in vivo, making their characterization and quantification difficult and often inaccurate. ${ }^{8-11}$ This major challenge is tackled via the development of miniaturized sensors, particles or dyes allowing in situ bio-analytical measurements. ${ }^{12-17}$ Their principle is to detect or react with unstable generated ROS or RNS, before species vanish or diffuse between compartments (organelles, cells, tissues, environment), henceforth providing higher quantitative and kinetic resolutions about undergoing processes. In this respect, multiple biomimetic approaches have been reported including hard material micro-reactors (e.g. glass or silicon based), synthetic soft material compartments and vesicles in which ROS or RNS can be produced, sequestrated and efficiently detected. ${ }^{16,18-23}$ Liposomes constitute a major category in this field, ${ }^{24-26}$ since they allow encapsulating enzymes during their preparation protocols comprising dry lipid film hydration, electroformation, sonication, extrusion, etc. ${ }^{26-30}$ In the liposome family, the small unilamellar vesicles (SUVs, typically $100 \mathrm{~nm}$ diameter) have found a wide range of biomedical applications as carriers for hydrosoluble moieties and enzymes. ${ }^{31-34}$ A particular interest of liposomes is their membrane permeability to a wide variety of molecules, including gases (dioxygen being the enzyme co-substrate for families of oxidases and hydrogenases). ${ }^{35-37}$ This feature allows substrate molecules to reach the inside of the vesicles, wherein enzymes are entrapped and catalyze the conversion of substrates into products to be further delivered or detected. ${ }^{38-39}$

Micrometric liposomes, quoted as Giant Unilamellar Vesicles (GUVs), have found specific applications in the fields of membrane biophysics and recently of namely protocells, synthetic or artificial or minimal cells. ${ }^{27,40-42}$ The aim of these systems is to design a micro-compartment mimicking the living cell membrane, ${ }^{29,43}$ in which biological entities will be incorporated step by step, in a bottom-up route, and their activity studied in situ. The first step is usually to incorporate enzymes in the vesicle lumen or in their membrane. Lipidic GUVs offer the major advantage over other types of micro-vesicles to be easily formed, be stable and fully work in physiological media (buffered pH and 330 mOsm typical osmolarity) used for biochemical analyses. ${ }^{28,30,44}$ Besides, these objects 
can be easily manipulated individually and observed by optical microscopies (fluorescence microscopy in particular). Consequently, GUVs offer an excellent platform to study the enzymatic generation of ROS or RNS in minimal cells.

In the present study, we propose to monitor electrochemically the enzymatic production of hydrogen peroxide $\left(\mathrm{H}_{2} \mathrm{O}_{2}\right)$ at a single GUV. $\mathrm{H}_{2} \mathrm{O}_{2}$ is a central ROS because of its good stability (1-hour temporal range) in absence of biological scavengers (catalase, peroxidases, peroxiredoxins), its ability to diffuse across phospholipid membranes and act as a redox messenger, and this is the end-product of multiple types of oxidases ${ }^{45}$. We will monitor its production by a glucose oxidase (GOx, $160 \mathrm{kDa}$ dimer), since GOx has been widely studied and characterized in the literature ${ }^{46}$. This enzyme is a flavoprotein which catalyzes the oxidation of $\beta$-Dglucose to $\mathrm{D}$-glucono- $\delta$-lactone with a simultaneous production of hydrogen peroxide when molecular oxygen acts as the electron acceptor $^{47-49}$.

A common methodological issue for enzymatic synthetic cells is the temporal and quantitative control of the reactions. The main limitation consists in the controlled introduction of substrate molecules inside individual vesicles. This can be obtained by passive, and often slow diffusion across the phospholipid membrane, or following membrane modifications by either vesicle fusion, channel protein insertion or local disruption and micro-injection with a micropipette..$^{27}$, 50-51 Injection and fusion of compartments can be achieved as well in microfluidic droplet systems although neither large volume modifications, nor multiple injections on individual objects are usually possible. ${ }^{41,52}$ In the present work, in order to ensure a complete control of concentrations, an electromicroinjection technique was used to modify the internal medium of each GUV and trigger enzymatic reactions. Optical microscopy easily allows observing individual vesicles and their microinjection. When the GOx reaction is initiated, the released species, i.e. $\mathrm{H}_{2} \mathrm{O}_{2}$, is detected in real-time by electrochemistry.

Electrochemistry with microsensors has not been reported so far, to our knowledge, to monitor enzymatic reactions at single synthetic, artificial cells. The main advantage of microelectrochemistry relies on the kinetic and quantitative resolutions of amperometric detection methods. These methods are based on measurements of redox moieties concentrations (substrates or products), whatever the probed volume is (considering a homogenous concentration within). Recent technical advances for electrochemical sensors have allowed to decrease their spatial dimensions, reaching sub-micrometric size to probe attoliter volumes, with sensitivity reaching nanomolar detection limits. ${ }^{53-56}$ Ultramicroelectrodes (UME), and further nanoelectrodes, allow to detect the release of redox species at a single cell and single sub-cellular compartments (e.g. secretory vesicles or mitochondria) ${ }^{51}$, 57-58. Such approach was widely used to detect electroactive neurotransmitters (catecholamines) released by exocytosis at the membrane of single cells and even at single giant vesicles mimicking a secretory cell. ${ }^{59-60}$ Besides, electrochemical sensors are very suitable for in vivo and in vitro analyses of ROS and RNS since many of these species are electroactive at carbon, platinum or enzymemodified electrodes ${ }^{61-64}$. In particular, platinum or platinized microelectrodes are efficient to detect selectively $\mathrm{O}_{2}, \mathrm{O}_{2}{ }^{\circ-}$ and $\mathrm{H}_{2} \mathrm{O}_{2}{ }^{65}$ Consequently, electrochemical microsensors should open avenues for the monitoring of enzymatic events generating ROS in artificial cells.

This is the goal of the present work, which reports on the highly sensitive electrochemical monitoring with a platinized UME of low $\mathrm{H}_{2} \mathrm{O}_{2}$ quantities produced by GOx enzymes in a GUV. GUVs formed in presence of glucose were individually injected with defined quantities of GOx. The induced enzymatic reaction was monitored by the UME placed next to the microreactor membrane (principle schematized on Figure 1). $\mathrm{H}_{2} \mathrm{O}_{2}$ fluxes diffusing across the phospholipid bilayer were quantified in real-time and modulated by the addition of a scavenging enzyme, catalase. Results demonstrate that the release of a ROS detected at a single enzymatic GUV are comparable to a single living cell release.

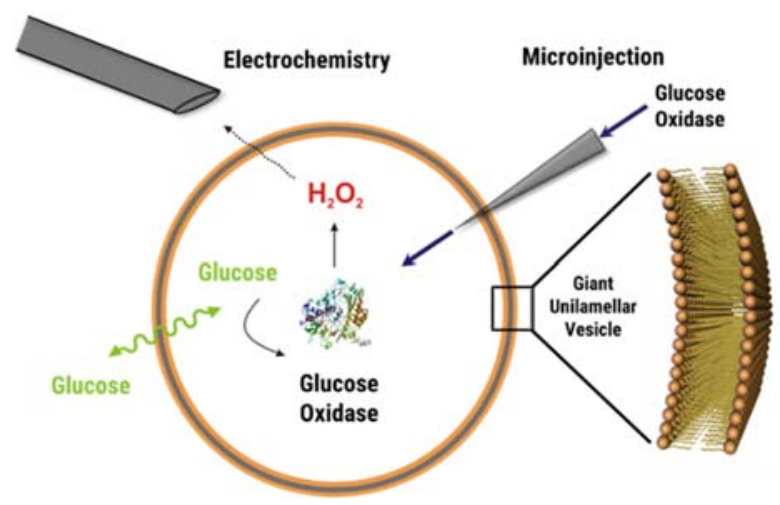

Figure 1. Schematic representation of the methodological approach. Glucose oxidase is microinjected inside a giant unilamellar vesicle (GUV) containing glucose. It leads to the enzymatic production of $\mathrm{H}_{2} \mathrm{O}_{2}$. The produced flux is probed in situ by electrochemistry with an ultramicroelectrode positioned at the vicinity of the GUV membrane.

\section{EXPERIMENTAL SECTION}

Reagents. Phospholipids origin from a Soybean polar extract (Avanti Polar Lipids, reference 541602; composition is $45.7 \mathrm{wt} / \mathrm{wt} \%$ phosphatidylcholine, $22.1 \mathrm{wt} / \mathrm{wt} \%$ phosphatidylethanolamine, $18.4 \mathrm{wt} / \mathrm{wt} \%$ phosphatidylinositol, $6.9 \mathrm{wt} / \mathrm{wt} \%$ phosphatidic acid and 
$6.9 \mathrm{wt} / \mathrm{wt} \%$ unknown) solubilized in chloroform (Sigma FR). KPi buffer was used for vesicles preparation, it is composed of $5 \mathrm{mM}$ TrizmaBase (Sigma FR), $30 \mathrm{mM} \mathrm{K}_{3} \mathrm{PO}_{4}$ (ABCR,), $30 \mathrm{mM} \mathrm{KH}_{2} \mathrm{PO}_{4}$ (Acros Organics), 1 mM MgSO, $7 \mathrm{H}_{2} \mathrm{O}$ (Sigma FR), $0.5 \mathrm{mM}$ EDTA (Sigma $\mathrm{FR}$ ) and $\mathrm{pH}$ was adjusted at 7.4 by addition of $\mathrm{H}_{3} \mathrm{PO}_{4} 98 \%$. All other experiments were conducted in phosphate buffer saline (3.9 $\mathrm{mM} \mathrm{NaH}_{2} \mathrm{PO}_{4}, 6.1 \mathrm{mM} \mathrm{Na}_{2} \mathrm{HPO}_{4}, 2.7 \mathrm{mM} \mathrm{KCl}, 138 \mathrm{mM} \mathrm{NaCl}$, Sigma FR, P5368) prepared by dissolving the aforementioned salts in pure MilliQ water (Millipore, Integral 3, $0.22 \mathrm{~mm}$ MilliPak filter). Hydrogen peroxide (Fluka Analytics), glucose (Sigma FR), glucose oxidase from Aspergillus Niger (Sigma Aldrich FR, G7141, $10 \mathrm{kU}$ ) and catalase (Sigma Aldrich FR, G7141, 2-5 kU) were solubilized and diluted in PBS at the desired concentrations.

Preparation of the giant unilamellar vesicles in physiological buffer. A very detailed protocol for giant unilamellar vesicles has been described elsewhere ${ }^{66}$ based on a dehydration-rehydration technique. Briefly, a natural extract from soybean was solubilized in pure chloroform at $10 \mathrm{mg} \cdot \mathrm{mL}^{-1}$ in a $10 \mathrm{~mL}$ pear-shaped flask. The solvent was evaporated with a rotary evaporator during 3 to $5 \mathrm{~h}$ (80-100 rpm) leading to the formation of a lipid film. KPi buffer was added in the flask allowing a gentle hydration of the film (12h at $4^{\circ} \mathrm{C}$ ). Glycerol was then added to the suspension (10 vol\%). Finally, a sonication step allowed the formation of SUV-MLVs (sonication bath, $3 \mathrm{~min}$ ).

GUVs were obtained from the SUV-MLVs suspension by dehydration-rehydration. $5 \mu \mathrm{L}$ of the suspension were dropped onto a glass coverslip and dehydration was conducted during $30 \mathrm{~min}$ in a vacuum desiccator with a vacuum membrane pump $(<100 \mathrm{kPa})$. The dehydrated lipids form a beveled transparent film with salt crystals in the center (coffee-stain effect). The presence of glycerol prevents complete dehydration of the lipids. Final rehydration was obtained by addition of PBS $(0.5 \mathrm{~mL})$ onto the coverslip. Osmotic gradients allow the swelling of GUVs on lipid reservoirs. After 10-15 min of equilibrium, the vesicles suspension could be transferred onto treated glass slides for immobilization of the GUVs.

Preparation of microscopy slides. Glass slides were cleaned with ethanol and milliQ water and dried under pressurized air flow. Surface activation was conducted with an oxygen plasma (Harrick Plasma, PDC-002) for 10 min. SU8-2002 epoxy photoresist (Microchem) was then spin coated on the slides (100 rpm $\cdot \mathrm{s}^{-1}$ ramp to $1000 \mathrm{rpm}$ then applied during $1 \mathrm{~min}$ ). The photoresist was pre-baked at $95^{\circ} \mathrm{C}$ for $5 \mathrm{~min}$ on a hotplate, UV exposed at $40 \mathrm{~mW} \cdot \mathrm{cm}^{-2}$ during $8 \mathrm{~s} \mathrm{(Kloe,} \mathrm{UV} \mathrm{Kub)} \mathrm{and} \mathrm{post-baked} \mathrm{at} 95^{\circ} \mathrm{C}$ during 5 min on a hotplate.

Microscopy observations and micromanipulations. All images were obtained on an inverted epifluorescence microscope (Leica STP-6000) with a 20x dry objective (Leica HCX PL Fluotar L, IP1, NA 0.4) in Differential Interference Contrast (DIC) widefield mode. Imaging was performed with MetaMorph software (from Molecular Devices). Microinjection and electrochemistry experiments were performed with manual micromanipulators using mechanical or piezoelectric (PZT) control of translation stages (ThorLabs PCS-5200).

Electro-microinjections. Vesicles were electro-microinjected with a glass micropipette formed from a glass capillary (WPI, TW100F4) pulled with a pipette puller (Narishige, PC-100) with parameters preliminary determined to provide pipette tips with a diameter below $1 \mu \mathrm{m}$ (heat level $=82$, force $=2.45 \mathrm{~N}$ ). In the pipette, a platinum wire (Good Fellow PT005140) was inserted and connected to an electric pulse generator (Digitimer DS2A-MkII). When the tip of the pipette is in touch with the vesicle membrane, the application of several electric pulses $(40 \mathrm{~V}, 20 \mathrm{~ms})$ allows the formation of a local pore in the membrane. The pipette was moved simultaneously to application of pulses leading to its penetration inside the vesicle. The membrane reorganized around the pipette tip, without showing invaginations nor deformations. Then, the solution contained in the pipette was injected with help of an air injector (Eppendorf FemtoJet). As function of the injection duration and pressure, pipette tip dimensions (opening diameter mostly), as well as of the vesicle initial diameter-volume, the injected volume could not a priori be determined but was calculated by measuring the increase of the vesicle diameter on images. This allowed to calculate intra-vesicular enzyme concentrations.

Fabrication of modified ultra-microelectrodes. Carbon fiber-based ultra-microelectrodes were used as working electrode for all electrochemical detection. The fabrication protocol has been previously described in detail. ${ }^{67-68}$ Briefly, individual carbon fibers (10 $\mu \mathrm{m}$ in diameter, Cytec Engineered Materials, reference Thornel P-55S) were sealed into pulled-glass capillaries (1 mm external diameter, WPI, reference TW100F-4). The protruding carbon fibers were insulated by electrochemical deposition of poly(oxyphenylene) following a literature procedure. The tip of the insulated carbon fiber was then polished at an angle of $45^{\circ}$ on a microgrinder (WPI, model 48000, roughness $1 \mu \mathrm{m}$ ) to expose a clean, elliptical carbon surface. The polished carbon surface was then platinized by reducing hydrogen hexachloroplatinate (Sigma FR, reference 262587) in the presence of lead acetate (Sigma FR) at $-60 \mathrm{mV} v$ s. $\mathrm{Ag} / \mathrm{AgCl}$. The platinization process was followed by chronoamperometry and interrupted when the electrical charge reached $10 \mu \mathrm{C}$. This value was calculated regarding the surface of the electrode and in order to reach the ratio of $0.1 \mu \mathrm{C} \cdot \mu \mathrm{m}^{-2}$ which corresponds to the optimal activity of the electrode for the detection of hydrogen peroxide ${ }^{64}$.

Electrochemical measurements. Cyclic voltammetry and chronoamperometry measurements (Biologic VSP-300 equipped with a low current unit) were performed in a 2-electrode setup, including a Black-Platinum modified carbon fiber ultramicroelectrode (10 $\mu \mathrm{m}$ diameter) as working electrode and an AgCl-coated Ag wire (GoodFellow AG005160) used both as pseudo-reference and counter electrodes. All electrochemical measurements were performed on the microscope platform and in a Faraday cage.

\section{RESULTS AND DISCUSSION}

\section{Electrochemical detection of hydrogen peroxide with an UME at a GUV}

The first experimental step consisted in depositing on a microscope slide individual GUVs formed by rehydration in the buffer solution. GUVs in suspension were left to sediment by gravity. The glass slide treatment based on a SU8-type resin coating allowed 
a sufficient adhesion of the vesicles to the surface. After $\sim 10$ min of sedimentation, most of the GUVs had settled and were immobile. The different electrodes used for the electro-microinjection and for electrochemical monitoring were placed in the solution (see Figure 2). The micropipette for injection and the platinized ultramicroelectrode were both micromanipulated and approached under microscopy observation next to an immobile GUV connected to a lipid reservoir. The electrochemical sensor was poised at the oxidation potential of $+0.35 \mathrm{~V} v s$. $\mathrm{Ag} / \mathrm{AgCl}$ and its response monitored by amperometry. It was left for current stabilization until a stable level with low drift was reached ( $20 \mathrm{~min})$. The detection potential was chosen based on the previouslystudied response of Black-Pt modified ultramicroelectrodes for $\mathrm{H}_{2} \mathrm{O}_{2}$ solutions, ${ }^{64,69-71}$ providing a maximum current intensity at the quasi-stationary plateau of the first $\mathrm{H}_{2} \mathrm{O}_{2}$ oxidation wave (see inset in Figure 3B). The in situ detection accuracy response of each UME was checked by microinjecting next to its surface hydrogen peroxide solutions (typically $0.5 \mathrm{mM}$ in PBS; see SI, Figure S1).

Then, injections were performed in GUVs. The micropipette tip was placed in contact with the GUV membrane by micromanipulation, and fast transient potentials $(4 \mathrm{~V}, 20 \mathrm{~ms})$ were applied locally to depolarize the vesicle membrane and facilitate the tip insertion inside the vesicle. The success rate of this step is very high $(>90 \%)$ owing to the electric field application whereas it is 20-fold less efficient when a simple mechanical pressure is applied on the membrane. The electro-microinjection method is less susceptible to the mechanical tension of the vesicle membrane for its penetration. After the pipette was inserted inside the vesicle, the membrane found its native position, without any invagination, nor bursting or size change of the GUV. The vesicle volume directly increased upon an injection. Measurement of the diameter variations by microscopy allowed estimating with good precision the injected volumes $(\Delta r \geq 10 \%$, i.e. $\Delta V \geq 30 \%)$, and therefore the final concentrations of the injected compounds. After injection, the pipette could be removed without observing any clear loss of internal medium nor flattening of the GUV.

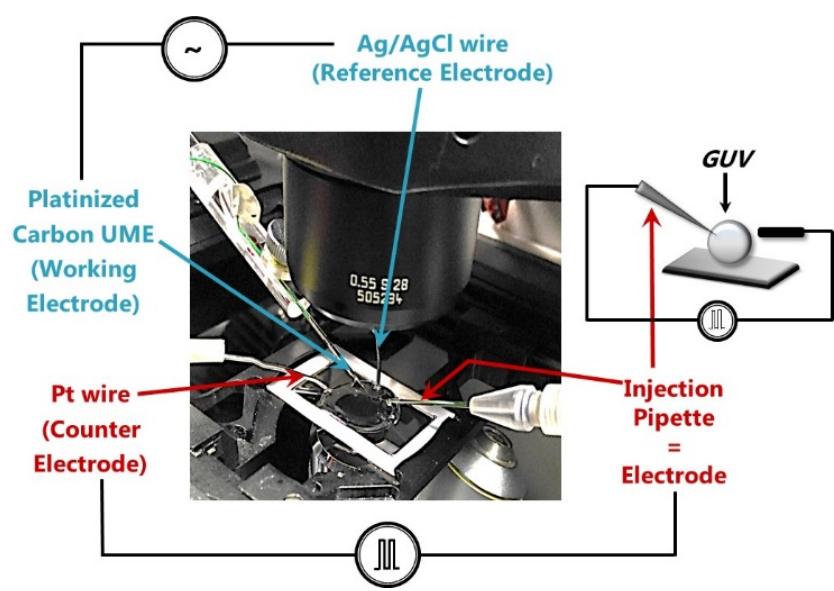

Figure 2. Image of the experimental setup. The solution containing the vesicles was deposited on a slide placed on the microscope stage. The two electrodes used for electro-microinjection were connected to a generator of electric pulses: the injection pipette was equipped with a platinum wire and a second platinum wire was used as counter electrode. Two other electrodes used for electrochemical detection were connected to a potentiostat: a platinized carbon ultramicroelectrode was used as the working electrode and an $\mathrm{AgCl}-\mathrm{coated} \mathrm{Ag}$ wire as a reference electrode. The schematic representation on the right is not drawn at scale.

Simultaneously, the platinized UME was positioned at a micrometric distance from the vesicle membrane using a second micromanipulator. The UME was preferentially approached from the side of the GUV, with its surface perpendicular to the bottom glass surface and parallel to the GUV membrane (see Figure 3A). This allows an accurate positioning of the electrode surface in order to maximize the collection efficiency of the hydrogen peroxide fluxes coming from a single vesicle. A subsequent injection of a $\mathrm{H}_{2} \mathrm{O}_{2}$ solution ( $2.5 \mathrm{mM}$ initial concentration; injected volume $\mathrm{V}=70 \mathrm{pL}$ ) within the $\mathrm{GUV}$ led to a rapid current increase as depicted on Figure 3B. The rise-time of the current variation was of about $5 \mathrm{~s}$ in this representative experiment. This duration depends on several parameters, independently from the time-response of the UME $(<1 \mathrm{sec}$.), including: the distance between the sensor surface and the vesicle membrane (see further studies), this latter changing during the vesicle injection and growth, the injection flow inside the vesicle corresponding to variations of mass transfer at the membrane, the species permeation across the GUV, etc. When the UME is placed next to the vesicle membrane and fast injections are processed in small vesicles (large and rapid volume variations), the response-time to an $\mathrm{H}_{2} \mathrm{O}_{2}$ injection can reach 1 sec.

Moreover, the detected response is undoubtedly due to $\mathrm{H}_{2} \mathrm{O}_{2}$ oxidation since this is the only electroactive species added to the solution (see also further results based on the enzymatic $\mathrm{H}_{2} \mathrm{O}_{2}$ production). Injections of PBS buffer were also performed as a control experiment, showing no current variation while the GUV volume increased. Since the electrode was positioned outside the vesicle, the current variations observed upon an injection of $\mathrm{H}_{2} \mathrm{O}_{2}$ meant that it diffuses across the phospholipid membrane to the outer solution. This result agrees with phospholipid membrane permeability for $\mathrm{H}_{2} \mathrm{O}_{2}$, as widely reported in literature ${ }^{454415}$. ${ }^{45}$ When the injection was stopped, the current decreased slowly until it reached the baseline level. The shape of the signal decay occurring after the injection depicts the diffusion profile of $\mathrm{H}_{2} \mathrm{O}_{2}$ from the inside to the outside of the liposome, until complete depletion. 

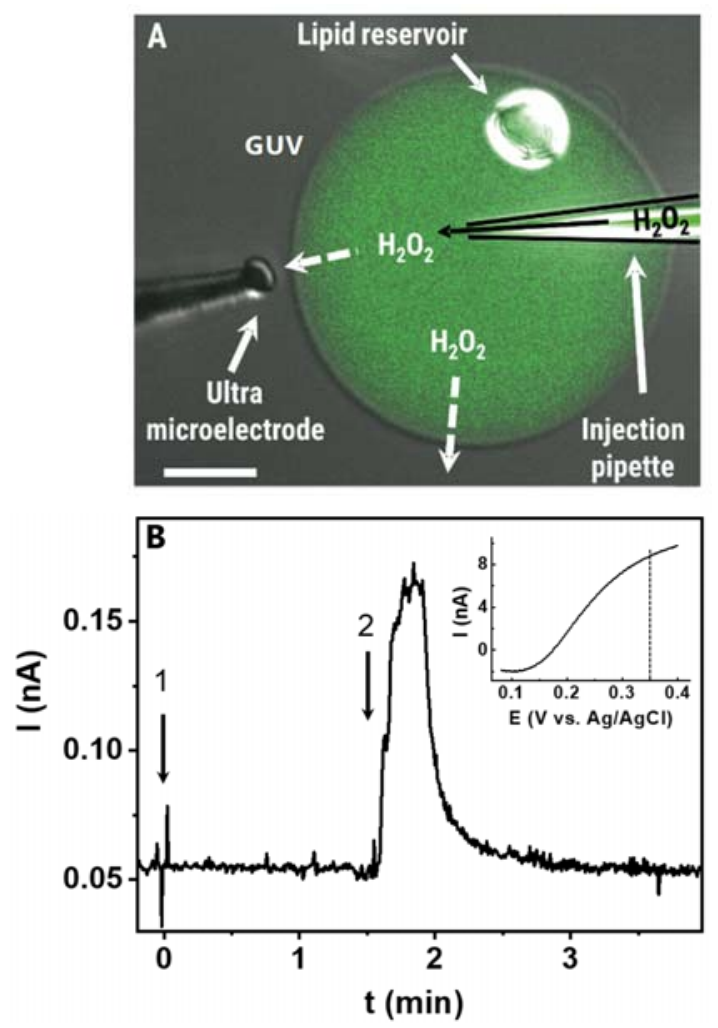

Figure 3. (A) Experiment of electro-microinjection of a hydrogen peroxide solution ( $2.5 \mathrm{mM}$ in PBS $10 \mathrm{mM}, \mathrm{pH} 7.4$ ) inside a GUV observed by microscopy, and simultaneous detection of $\mathrm{H}_{2} \mathrm{O}_{2}$ flux by electrochemistry. $60 \mu \mathrm{M}$ fluorescein was added to the injected solution and observed by fluorescence $(\lambda$ exc. $=488 \mathrm{~nm})$ at the end of the microinjection. Scale bar $=25 \mu \mathrm{m}$. The injection pipette shape has been digitally drawn to make it clearer. (B) The $\mathrm{H}_{2} \mathrm{O}_{2}$ flux was detected by chronoamperometry at $+0.35 \mathrm{~V} \mathrm{vs}$. $\mathrm{Ag} / \mathrm{AgCl}$ with an ultramicroelectrode. The pipette was first inserted within the GUV by electro-microinjection resulting in a current artefact, indicated by the first arrow (1), and positioned at the vicinity of the membrane. The hydrogen peroxide solution was then injected inside the GUV (2). Experiment was performed in phosphate buffer ( $300 \mathrm{mOsm}, \mathrm{pH}$ 7.4). Inset: oxidation wave of $\mathrm{H}_{2} \mathrm{O}_{2}(0.5 \mathrm{mM}$ in PBS) recorded by cyclic voltammetry with a platinized carbon fiber-based UME $\left(10 \mathrm{mV} \cdot \mathrm{s}^{-1}\right)$ The dashed line indicates the potential used for the chronoamperometry experiment (+ $0.35 \mathrm{~V} v \mathrm{vs} . \mathrm{Ag} / \mathrm{AgCl})$, which corresponds to the oxidation plateau.

Chronoamperometry is well-suited to detect the diffusion in solution of a species after its generation or release by a microcompartment, such like a living cell or a synthetic vesicle herein. In principle, the current intensity is directly related to the number of oxidized or reduced redox molecules (number of electrons transferred as well) according to the Cottrell equation ${ }^{72}$. During, and to some extent after the injection, the mass transport is dominated by convection within the GUV. The diffusion of $\mathrm{H}_{2} \mathrm{O}_{2}$ across the phospholipid membrane depends on the partition coefficient $(P)$ of the species, meaning that the flux reaching the membrane is slowed down depending on $P$.

Moreover, the working condition found here differs from what happens in bulk condition where a stable concentration of the redox species exists. The diffusion layer formed at the electrode surface during the electrochemical faradaic process implies that a concentration gradient of the species is created next to the vesicle: the closer to the electrode, the lower the concentration of hydrogen peroxide. Fluxes of $\mathrm{H}_{2} \mathrm{O}_{2}$ are then directed towards the electrode due to entropic effects. Therefore, the signal reported on Figure $3 \mathrm{~B}$ is not due to diffusion solely and does not allow the same direct conversion of the current as a function of the concentration as in bulk stationary conditions. The UME works rather as a local collector and sensor at the vesicle border of the flux of hydrogen peroxide generated by the confined enzymatic system.

\section{Performing the GOx catalysis in a single GUV and detecting the local $\mathrm{H}_{2} \mathrm{O}_{2}$ production}

The enzymatic reaction in single GUVs was induced by microinjections of low quantities of glucose oxidase (GOx from Aspergillus Niger). In a recent study, ${ }^{73}$ we have defined the experimental conditions allowing a kinetic and quantitative control of the GOx activity in the same GUVs as used herein. A hydrogen peroxide fluorescent assay (Amplex Red fluorogenic probe and peroxidase enzyme) revealed by laser scanning confocal microscopy on the GUVs that such liposomes allow a passive diffusion of glucose and resorufin (fluorescent reporter of the Amplex Red assay). It has been shown that these vesicles are however not permeable to glucose oxidase and horseradish peroxidase enzymes, which remained sequestrated after injections for tens of minutes. Here, the GUV suspension was prepared in presence of $1 \mathrm{mM}$ glucose so that the substrate is homogeneously distributed and available inside 
and outside the vesicles. A GOx solution $\left(2.5 \mathrm{U} \cdot \mathrm{mL}^{-1}\right)$ was micro-injected inside a single vesicle (Figure 4A). A preliminary study was conducted to determine the optimal substrate-to-enzyme concentrations ratio to get a rapid initial kinetic phase allowing a fast $\mathrm{H}_{2} \mathrm{O}_{2}$ production detectable by electrochemistry (Figure S2). The representative response reported in Figure $4 \mathrm{~B}$ corresponds to the activity of only $\sim 20$ micro-units of enzymes working in a $10 \pm 0.5 \mathrm{~nL}$ volume.

Because of the semi-permeability of the GUV membrane for glucose (related to the composition in phospholipids reported in the experimental section), the substrate concentration in the vesicles should reach a constant value and lead to an enzymatic stationary state. Thus, after $\mathrm{GOx}$ injection and internal solution homogenization, a continuous production of $\mathrm{H}_{2} \mathrm{O}_{2}$ by the micro-reactor is expected. While microinjecting the enzyme (start after pulses depicted by the star in Figure 4B), the vesicle volume increased and the ultramicroelectrode was positioned at few micron-distance from the membrane. An increase of oxidation current was rapidly observed, corresponding to the initial phase of the enzymatic reaction. Then, the current intensity progressively reached a plateau corresponding to an increase of $15 \pm 3 \mathrm{pA}$ (measured from 5 independent experiments). The observed kinetic is reminiscent of two phases: first, the enzymatic consumption of the vesicle content in glucose and then the equilibrium between glucose permeation into the vesicle and the enzymatic production of $\mathrm{H}_{2} \mathrm{O}_{2}$ followed by its diffusion to the outside medium. The $\mathrm{H}_{2} \mathrm{O}_{2}$ production rate should thus depend on the glucose concentration available in the vesicle internal medium and consequently in the surrounding medium. This was observed when decreasing glucose to $100 \mu \mathrm{M}$ (see result in Figure S3), which led to lower $\mathrm{H}_{2} \mathrm{O}_{2}$ flux (about 10fold). These results report qualitatively on the proper working of the GOx reaction inside a GUV within a set of similar conditions (GUV dimensions, injections, pipettes, UME size, etc.). The signal observed at single vesicles remains complex and would need further understanding to be quantitatively interpreted.
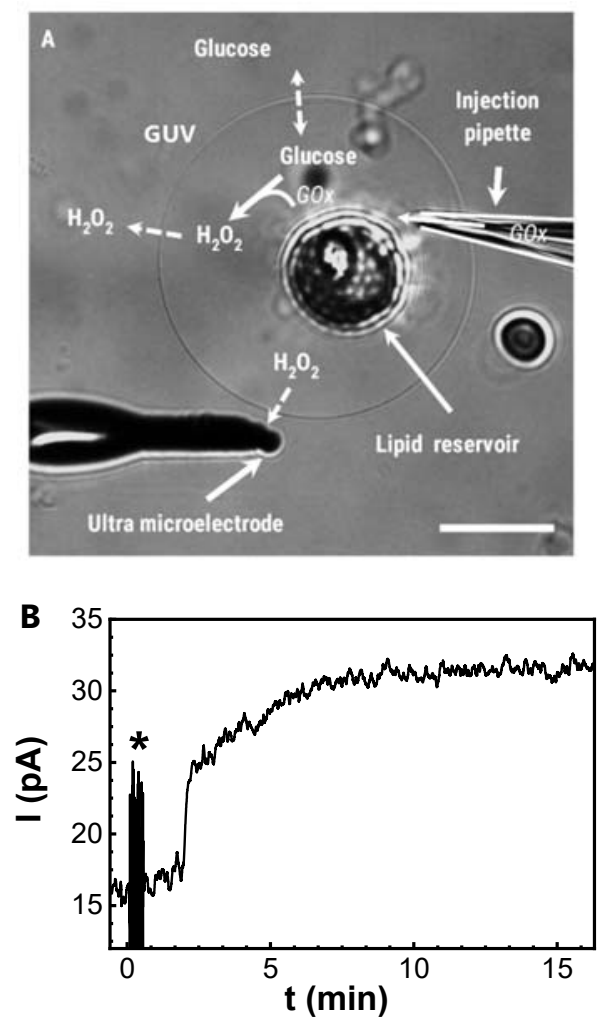

Figure 4. (A) Electro-microinjection of glucose oxidase (GOx, $2.5 \mathrm{U} \cdot \mathrm{mL}^{-1}$ solution in the pipette) inside a GUV (initial diameter: $41 \mu \mathrm{m}$; final diameter: $60 \mu \mathrm{m}$ ) containing $1 \mathrm{mM}$ glucose. $\mathrm{H}_{2} \mathrm{O}_{2}$ is produced, diffuses across the membrane and is detected in situ at the surface of an ultramicroelectrode by electrochemistry. Scale bar $=25 \mu \mathrm{m}$. The injection pipette shape has been digitally drawn to make it clearer. (B) The current intensity was recorded by chronoamperometry at $+0.35 \mathrm{~V} v$ s. $\mathrm{Ag} / \mathrm{AgCl}$. Spikes notified by a star $\left({ }^{*}\right)$ are due to electric pulses used for electro-microinjection. The experiment was performed in PBS (330 mOsm) at pH 7.4.

\section{Control experiments to assess for the selectivity of $\mathrm{H}_{2} \mathrm{O}_{2}$ measurements at $\mathrm{GOx}$-in-GUVs}

Selectivity of the $\mathrm{H}_{2} \mathrm{O}_{2}$ measurements performed at single GUVs with GOx was assessed via three different experiments. In a first approach, catalase, the natural scavenging enzyme for $\mathrm{H}_{2} \mathrm{O}_{2}$, was used (Figure 5A). An experiment similar to the one shown in Figure 4B was performed; GOx was electro-microinjected inside a GUV and a plateau current was reached. Please note the excellent reproducibility of response (kinetic, amplitude) between the two different, independent experiments performed in equivalent conditions with GUVs of similar size. Then, the pipette was replaced by a second one containing a catalase solution, which was injected in the GUV's outer environment close to the ultramicroelectrode. The goal was to scavenge locally hydrogen peroxide molecules and decrease the flux reaching the electrode surface. This is exactly what was observed (Figure 5A). When the catalase 
injection was stopped, the current progressively raised to reach a level similar to the current before catalase; the effect was transitory as the injection was performed for only 30 seconds resulting ultimately in the dilution and diffusion of the catalase solution in the bulk. The response recovery confirmed that the production of $\mathrm{H}_{2} \mathrm{O}_{2}$ was continuous and that variations were not due to any artefact at the electrode or the vesicle membrane. In a second experiment (Figure 5B), glucose oxidase and catalase were simultaneously present in the pipette and injected within a GUV, while the UME was positioned next to the membrane. Following injection, a weak signal was detected (low Signal/Noise ratio), of much lower amplitude than with GOx alone in the GUV due to the in situ scavenging effect of catalase. This reinforces the identification of $\mathrm{H}_{2} \mathrm{O}_{2}$ as the redox species leading to the measured amperometric current.

Eventually, the typical experiment shown in Figure $4 \mathrm{~B}$ was reproduced with an ultramicroelectrode poised at a $0 \mathrm{Vvs}$. $\mathrm{Ag} / \mathrm{AgCl}$ potential, not allowing the detection of $\mathrm{H}_{2} \mathrm{O}_{2}$ (neither by oxidation nor reduction). ${ }^{65}$ Indeed, the chrono-amperometric curve in Figure $5 \mathrm{C}$ does not display any current rise related to the flux of $\mathrm{H}_{2} \mathrm{O}_{2}$ produced by $\mathrm{GOx}$ in the GUV. Only low background current oscillations were measured. As well, when the ultramicroelectrode was moved away from the GUV, the current stayed at a similar level (small increase due to convection) showing that no redox species was specifically detected near the active GUV or in the bulk in this condition. Consequently, both control experiments demonstrated that the current variations detected under $\mathrm{GOx}$ injection inside a GUV could only be assigned to the local flux of $\mathrm{H}_{2} \mathrm{O}_{2}$ produced and diffusing across the membrane.

A

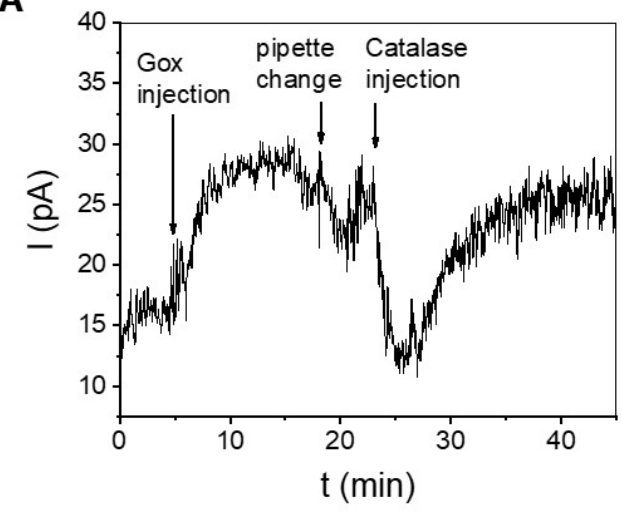

B

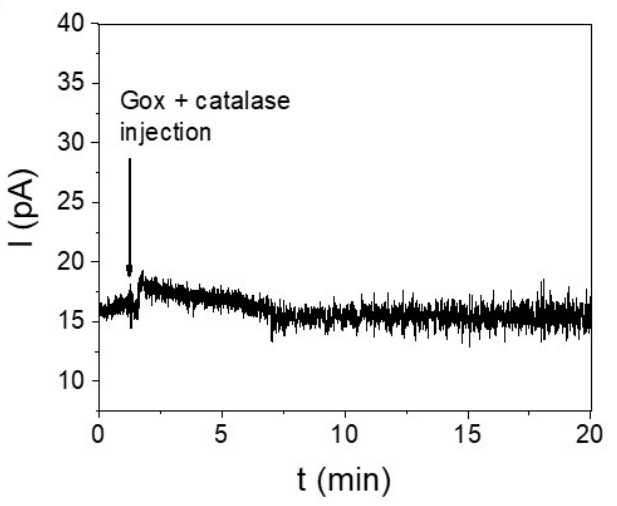

C

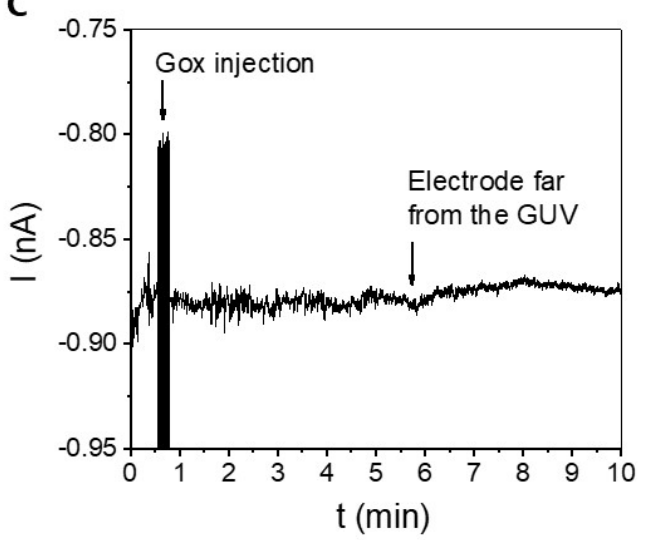

Figure 5. Control experiments to assess on the selectivity of the chronoamperometric detection of $\mathrm{H}_{2} \mathrm{O}_{2}$ produced by GOx in GUVs. Experimental conditions are the same as in Fig. 4, except: in (A), after the microinjection of glucose oxidase (GOx, $2.5 \mathrm{U} \cdot \mathrm{mL}^{-1}$ in PBS) inside a GUV, the micropipette was withdrawn and replaced by another pipette containing catalase $\left(\sim 1000 \mathrm{U} \cdot \mathrm{mL}^{-1}\right.$ in PBS$)$; at $\mathrm{t}=23 \mathrm{~min}$, catalase 
was injected (30 s duration) in the environment of the ultramicroelectrode next to the GUV membrane; in (B), with another GUV, GOx and catalase were simultaneously present in the micropipette and injected inside the GUV; in (C), chronoamperometry was recorded at $0 \mathrm{~V}$ instead of $+0.35 \mathrm{~V}$ vs. $\mathrm{Ag} / \mathrm{AgCl}$ used in $(\mathrm{A})$. GOx was first micro-injected (artefacts on the curve); at $\mathrm{t}=5.5 \mathrm{~min}$, the ultramicroelectrode was placed at further distance from the GUV (about $100 \mu \mathrm{m}$ ). The experiments were performed in PBS (330 mOsm) at pH 7.4 .

\section{Quantification of enzymatic $\mathrm{H}_{2} \mathrm{O}_{2}$ production in GUVs}

The in situ sensitivity of the electrochemical measurements was assessed by positioning the ultramicroelectrode surface at various distances from the vesicle membrane. The distance was first changed successively from a far position, i.e. at about $100 \mu \mathrm{m}$, to the closest position from the membrane, i.e. 1-2 $\mu \mathrm{m}$, without touching it. Figure 6A depicts successive position changes. The electrode was sequentially placed at the furthest and closest position from the membrane, resulting in a square wave signal (Figure 6A, between 20 and $40 \mathrm{~min}$ ). At the closest position, the current intensity is relatively high ( $\Delta \mathrm{I} \sim 15 \mathrm{pA})$, whereas it decreases very fast to reach the baseline current level when the electrode is far away from the membrane. The "far-close" sequence was repeated 4 times. The current intensities at the two positions were reproducible, demonstrating the fast and sensitive response of the electrode to the $\mathrm{H}_{2} \mathrm{O}_{2}$ generated flux. Four other distances between the electrode and the GUV were tested to evaluate accurately the sensitivity of the electrochemical response as a function of the distance from the GUV (Figure 6A, from 40 to 55 min and Figure $6 \mathrm{~B})$. We determined that the current intensity evolves linearly with the distance between the electrode and the GUV membrane (Figure $6 \mathrm{~B}$ ); the slope was calculated at: $-0.11 \mathrm{pA} \cdot \mu \mathrm{m}^{-1}$. On Figure $6 \mathrm{~B}$, the faradaic current variation $(\Delta \mathrm{I})$, independent of the current baseline (initial value of the current before injection), was plotted as function of the distance. The result demonstrates the very high sensitivity provided by in situ amperometric measurements with an ultramicroelectrode, similarly to measurements of ROS release at cell membranes. ${ }^{67-68,74}$ In addition, amperometry informs instantaneously (as function of the detection time-resolution) about the concentration observed by the electrode, which is a more realistic information than a chemical or biochemical conversion of a probe (enzyme-dependent) to a stable fluorescent compound such as in the Amplex Red assay. The amperometric current can be directly converted into a detected flux due to the enzymatic activity.
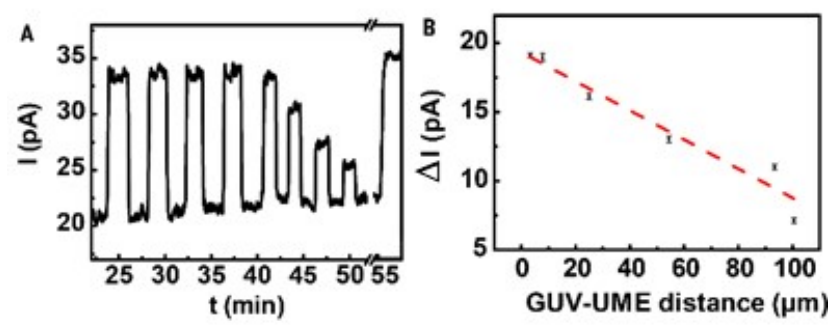

Figure 6. Detection of $\mathrm{H}_{2} \mathrm{O}_{2}$ produced by the GOx reaction in a GUV and evolution of the current signal with the distance between the membrane and the ultramicroelectrode (UME). (A) Chronoamperometric response at $+0.35 \mathrm{~V} v$ s. Ag/AgCl. The square wave shape signal was obtained by sequentially moving the electrode at various distances from the GUV membrane. (B) The current variation between plateau and baseline levels $(\Delta \mathrm{I})$ is plotted in function of the distance between the GUV and the electrode to estimate the sensibility of the measurement with the distance.

The GOx-modified GUV (i.e. GOx in GUV) acts as a continuous $\mathrm{H}_{2} \mathrm{O}_{2}$-producing microreactor from where the species diffuse freely in the three directions of the surrounding volume. The $\mathrm{H}_{2} \mathrm{O}_{2}$ concentration is rapidly diluted in the bulk after crossing the membrane. A high $\mathrm{H}_{2} \mathrm{O}_{2}$ concentration gradient surrounding the vesicle is formed, explaining the high dependency of the signal with the distance. Moreover, the $\mathrm{H}_{2} \mathrm{O}_{2}$ enzymatic production by GOx in GUVs was stable for tens of minutes reaching a one-hour timescale (Figure 4B to 6A). In order to perform such long-term experiments, the electrode-GUV distance had to be kept constant, a value of $\sim 3 \mu \mathrm{m}$ (Figure 4A) resulted in only a $\sim 2 \%$ loss of the plateau current. This distance is necessary to avoid any contact between the electrode and the membrane. Indeed, in case of contact, we observed that the sensitivity is lowered (data not shown), probably due to a passivation of the electrode surface by phospholipids. The contact may also lead to the oxidation of phospholipids of the external leaflet and ensuing membrane damages.

Further, a refined quantitative analysis from the typical data reported on Figure 4B (similarly for Figure 5A) was performed. Oxidation current variations were integrated over time to access to the coulometric charge and therefore to the quantity of $\mathrm{H}_{2} \mathrm{O}_{2}$ detected versus time based on the Faraday's law (Eq. 1):

$$
n=\frac{Q}{z \cdot \mathcal{F}}=\frac{\int_{0}^{t} I_{t} \cdot d t}{z \cdot \mathcal{F}}
$$


with $n$ the quantity of species (mol) oxidized at the electrode surface, $Q$ the faradaic charge $(\mathrm{C}), z$ the number of electrons exchanged in the reaction, $\mathcal{F}$ the Faraday constant $\left(\mathrm{C} \cdot \mathrm{mol}^{-1}\right), I_{t}$ the current intensity $(\mathrm{A})$ during a time interval $d t$. Figure 7 represents the detected quantity of $\mathrm{H}_{2} \mathrm{O}_{2}$ over time, calculated by integrating the current variation, for the typical experiment shown on Figure 4B. The variation follows a linear trend, whose slope provides the mean reaction rate, calculated as $4.0 \times 10^{-15} \mathrm{~mol}^{\circ} \cdot \mathrm{min}^{-1}$ of $\mathrm{H}_{2} \mathrm{O}_{2}$ by 20 micro-units of GOx in the GUV, i.e. $\approx 2.0 \times 10^{-10} \mathrm{~mol} \cdot \mathrm{min}^{-1} \mathrm{u}^{-1}$.

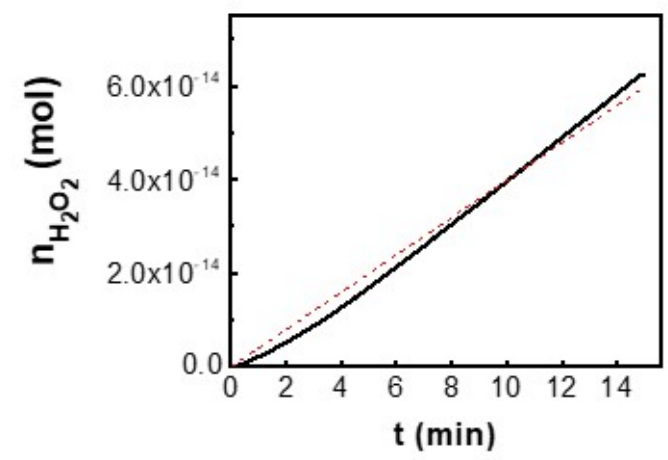

Figure 7 Quantity of hydrogen peroxide detected at the surface of a UME along the GOx activity achieved inside a GUV. This was calculated from the integration of the chronoamperometric signal reported in Figure $4 \mathrm{~B}$ (representative experiment). The dashed line corresponds to the linear regression used to fit the data $\left(r^{2}=0.99\right)$; the slope $\left(4.010^{-15} \mathrm{~mol} \cdot \mathrm{min}^{-1}\right)$ gives the reaction rate over the experiment time-scale.

The collection efficiency by the UME of the whole GUV signal can be calculated as the ratio of the UME surface collection over the whole vesicle external surface. In the representative experiment of Figure $4 \mathrm{~B}$, the collection efficiency is $2 \%$ (reaching $\approx 5 \%$ when considering a higher surface activity for the platinized UME). This meets our objective of sampling locally the $\mathrm{H}_{2} \mathrm{O}_{2}$ flux produced by the vesicle reactor, without affecting its functioning for instance by creating a strong concentration gradient around the whole vesicle or by electrogenerated products at the UME. The UME is used as a local sensor, observer of an $\mathrm{H}_{2} \mathrm{O}_{2}$ flux produced by the enzymatic activity. We assume that the flux detected at one location of the membrane is representative of the mean flux produced by the GUV. The hypothesis is reinforced by our recent results with the same type of enzymatic GUVs analyzed by fluorescence confocal microscopy ${ }^{73}$. The Amplex Red assay was used to image the bi-enzymatic system composed of GOx and HRP (horseradish peroxidase); we observed that resorufin, the end-product of the reactions, was emitted over the whole surface of the GUV meaning that the composition within the GUV volume was homogeneous at the time-scale of the experiment.

In addition, the flux detected at single "GOx in GUVs" can be compared with a bulk enzymatic experiment performed with the same composition (1 mM glucose, $2.5 \mathrm{U} \cdot \mathrm{mL}^{-1} \mathrm{GOx}$ in PBS pH 7.4) and monitored with the same electrochemical sensors (Figure S2). The conversion of the oxidation current variations (Figure $\mathrm{S} 2 \mathrm{~A}$ ) into accumulated $\mathrm{H}_{2} \mathrm{O}_{2}$ concentrations based on the calibration curve of the ultramicroelectrode (Figure S2B) leads to a detected mean GOx activity of $5 \times 10^{-10} \mathrm{~mol} \cdot \mathrm{min}^{-1} \cdot \mathrm{u}^{-1}$. This value compares very well with the one estimated for the enzymatic GUV, this latter being a bit smaller since the reaction depends on multiple parameters including glucose permeation across the membrane and the estimation of injected enzyme quantity. Finally, these results show, as a proof of concept, that a highly sensitive, quantitative analysis of an enzymatic activity occurring in a single GUV can be performed based on the electrochemical detection of a redox product.

\section{CONCLUSION}

Giant unilamellar vesicles are widely considered as adequate minimal compartments to study enzymatic activities under spatialand time-scales closer to living systems than in usual bulk conditions. Coupling such minimal cell to an in situ electrochemical detection with an ultramicroelectrode provides a quantitative monitoring of the hydrogen peroxide produced by an oxidase, GOx herein to demonstrate the concept. The permeability properties of such phospholipidic vesicles allow the diffusion of various small species such as $\mathrm{H}_{2} \mathrm{O}_{2}$. Similarly, other reactive oxygen and nitrogen species including nitric oxide should cross the GUV membrane. This opens opportunities for the study of various enzymatic reactions especially with more complex reactional pathways such as those observed for NO-synthases. The introduction of membrane transporters and pore-forming proteins in GUV will favor the transport of compounds (charged, large size) which are unable to diffuse across the membrane. This represents a further step to study a broader range of enzyme activities, as long as the products are electroactive. The reconstitution of complex biochemical pathways in liposomes and their resolved analysis is eventually a pre-requisite for the development of artificial cells.

\section{AUTHOR INFORMATION}

\section{Corresponding Author}

Dr Stéphane Arbault, email : stephane.arbault@u-bordeaux.fr Tel.: +33540006851;

\section{Author Contributions}

The manuscript was written through contributions of all authors. All authors have given approval to the final version of the manuscript. 


\section{ACKNOWLEDGMENT}

This work was funded by the CNRS, CEA, Bordeaux INP, University of Bordeaux and Agence Nationale de la Recherche (ANR, Project NOSYNTHCELL, contract ANR-14-CE16-0015-02).

\section{Supporting Information}

The Supporting Information is available free of charge on the ACS Publications website. In the ESI section are reported: $1 /$ a hydrogen peroxide solution microinjection next to the ultramicroelectrode surface (image and amperometry); 2 / calibration curves versus $\mathrm{H}_{2} \mathrm{O}_{2}$ concentrations for platinized microelectrodes in conditions of measurements at GUVs; in homogeneous solution and during $\mathrm{H}_{2} \mathrm{O}_{2}$ production by the GOx activity; 3 / the amperometric monitoring of GOx activity from a GUV in presence of $0.1 \mathrm{mM}$.

\section{REFERENCES}

1. Moldogazieva, N. T.; Mokhosoev, I. M.; Feldman, N. B.; Lutsenko, S. V. Free Radic. Res. 2018, 52 (5), $507-543$.

2. Di Meo, S.; Reed, T. T.; Venditti, P.; Manuel Victor, V. Oxid. Med. Cell. Longev. 2016, 2016.

3. Winterbourn, C. C.; Kettle, A. J.; Hampton, M. B., Annual Review of Biochemistry, Vol 85, Kornberg, R. D., Ed. 2016 ; Vol. 85, pp 765-792.

4. del Rio, L. A. J. Exp. Bot. 2015, 66 (10), 2827-2837.

5. Sies, H.; Jones, D. P. Nat. Rev. Mol. Cell Biol. 2020, 21 (7), 363-383.

6. Zhang, Y.; Murugesan, P.; Huang, K.; Cai, H. Nat. Rev. Cardiol. 2020, 17 (3), 170-194.

7. Yang, X.; Li, Y.; Li, Y.; Ren, X.; Zhang, X.; Hu, D.; Gao, Y.; Xing, Y.; Shang, H. Front. Physiol. 2017, 8.

8. Yan, K.-C.; Sedgwick, A. C.; Zang, Y.; Chen, G.-R.; He, X.-P.; Li, J.; Yoon, J.; James, T. D. Small Meth. 2019,3 (7), 1900013.

9. Erard, M.; Dupre-Crochet, S.; Nusse, O. Am. J. Physiol-Reg. I. 2018, 314 (5), R667-R683.

10. Winterbourn, C. C. BBA-Gen. Subjects 2014, 1840 (2), 730-738.

11. Dikalov, S. I.; Harrison, D. G. Antioxid. Redox Sign. 2014, 20 (2), 372-382.

12. Wu, L.; Sedgwick, A. C.; Sun, X.; Bull, S. D.; He, X.-P.; James, T. D. Acc. Chem. Res. 2019, 52 (9), 2582-2597.

13. Su, Y.; Song, H.; Lv, Y. Microchem. J. 2019, 146, 83-97.

14. Ortega-Villasante, C.; Buren, S.; Blazquez-Castro, A.; Baron-Sola, A.; Hernandez, L. E. Free Radic. Biol. Med. 2018, 122, $202-220$.

15. Suzen, S.; Gurer-Orhan, H.; Saso, L. Molecules 2017, 22 (1), 181.

16. Seenivasan, R.; Kolodziej, C.; Karunakaran, C.; Burda, C. Chem. Rec. 2017, 17 (9), 886-901.

17. Zhang, R.; Zhao, J.; Han, G.; Liu, Z.; Liu, C.; Zhang, C.; Liu, B.; Jiang, C.; Liu, R.; Zhao, T.; Han, M.-Y.; Zhang, Z. J. Am. Chem. Soc. 2016, 138 (11), 3769-3778.

18. Vajrala, V. S.; Belaidi, F. S.; Lemercier, G.; Zigah, D.; Rigoulet, M.; Devin, A.; Sojic, N.; Temple-Boyer, P.; Launay, J.; Arbault, S. Biosens. Bioelectron. 2019, 126, 672-678.

19. Xu, J.; Jiang, D.; Qin, Y.; Xia, J.; Jiang, D.; Chen, H.-Y. Anal. Chem. 2017, 89 (4), 2216-2220.

20. Kim, H.-O.; Yeom, M.; Kim, J.; Kukreja, A.; Na, W.; Choi, J.; Kang, A.; Yun, D.; Lim, J.-W.; Song, D.; Haam, S. Small 2017, 13 (32), 1700818.

21. Hu, X.; Zhang, Y.; Xie, Z.; Jing, X.; Bellotti, A.; Gu, Z. Biomacromolecules 2017, 18 (3), 649-673.

22. York-Duran, M. J.; Godoy-Gallardo, M.; Jansman, M. M. T.; Hosta-Rigau, L. Biomater. Sci. 2019, 7 (11), $4813-4826$.

23. Zhang, Y.; Gal, N.; Itel, F.; Westensee, I. N.; Brodszkij, E.; Mayer, D.; Stenger, S.; Castellote-Borrell, M.; Boesen, T.; Tabaei, S. R.; Hook, F.; Stadler, B. Nanoscale 2019, 11 (24), 11530-11541.

24. Guan, H.; Gong, D.; Song, Y.; Han, B.; Zhang, N. Colloid. Surface A. 2019, 574, 260-267.

25. Zhu, C.; Itel, F.; Chandrawati, R.; Han, X.; Stadler, B. Biomacromolecules 2018, 19 (11), 4379-4385.

26. Deng, N. N.; Yelleswarapu, M.; Huck, W. T. S. J. Am. Chem. Soc. 2016, 138 (24), 7584-7591.

27. Dimova, R., Annual Review of Biophysics, Vol 48, Dill, K. A., Ed. 2019; Vol. 48, pp 93-119.

28. Lefrancois, P.; Goudeau, B.; Arbault, S. Integr. Biol. 2018, 10 (7), 429-434.

29. Walde, P.; Cosentino, K.; Engel, H.; Stano, P. ChemBioChem 2010, 11 (7), 848-865.

30. Pott, T.; Bouvrais, H.; Meleard, P. Chem. Phys. Lipids 2008, 154 (2), 115-119.

31. Liu, Y.; Castro Bravo, K. M.; Liu, J. Nanoscale horiz. 2021, (6), 78-94.

32. Roberts, T. C.; Langer, R.; Wood, M. J. A. Nat. Rev. Drug Discov. 2020, 19 (10), 673-694.

33. Cascione, M.; De Matteis, V.; Leporatti, S.; Rinaldi, R. Front. Bioeng. Biotechnol. 2020, 8, 566767.

34. Kraft, J. C.; Freeling, J. P.; Wang, Z.; Ho, R. J. Y. J. Pharm. Sci. 2014, 103 (1), 29-52.

35. Rems, L.; Viano, M.; Kasimova, M. A.; Miklavcic, D.; Tarek, M. Bioelectrochem. 2019, 125, 46-57.

36. Briuglia, M.-L.; Rotella, C.; McFarlane, A.; Lamprou, D. A. Drug Deliv. Transl. Re. 2015, 5 (3), $231-242$.

37. Chang, H.-I.; Yeh, M.-K. Int. J. Nanomed. 2012, 7, 49-60.

38. Walde, P.; Ichikawa, S. Biomol. Eng 2001, 18 (4), 143-177.

39. Piwonski, H. M.; Goomanovsky, M.; Bensimon, D.; Horovitz, A.; Haran, G. Proc. Natl. Acad. Sci. U. S. A. 2012, 109 (22), E1437-E1443.

40. Jorgensen, I. L.; Kemmer, G. C.; Pomorski, T. G. Eur. Biophys. J. Biophy. 2017, 46 (2), 103-119.

41. Robinson, T. Adv. Biosys. 2019, 3 (6), 1800318.

42. Matosevic, S. Bioessays 2012, 34 (11), 992-1001.

43. York-Duran, M. J.; Godoy-Gallardo, M.; Labay, C.; Urquhart, A. J.; Andresen, T. L.; Hosta-Rigau, L. Colloid. Surface. B 2017, $152,199-213$.

44. Breton, M.; Amirkavei, M.; Mir, L. M. J. Membr. Biol. 2015, 248 (5), 827-835.

45. Moeller, M. N.; Lancaster, J. R., Jr.; Denicola, A., Free Radical Effects on Membranes, Matalon, S.; Patel, R. P., Eds. 2008; Vol. 61, pp 23-+.

46. Bankar, S. B.; Bule, M. V.; Singhal, R. S.; Ananthanarayan, L. Biotechnol. Adv. 2009, 27 (4), 489-501.

47. Bentley, R., The Enzymes. Academic Press: New York, 1963; Vol. 7, p 567-586.

48. Chan, T. W.; Bruice, T. C. J. Am. Chem. Soc. 1977, 99 (7), 2387-2389.

49. Leskovac, V.; Trivic, S.; Wohlfahrt, G.; Kandrac, J.; Pericin, D. Int. J. Biochem. Cell Biol. 2005, 37 (4), $731-750$.

50. Karlsson, M.; Nolkrantz, K.; Davidson, M. J.; Stromberg, A.; Ryttsen, F.; Akerman, B.; Orwar, O. Anal. Chem. 2000,72 (23), $5857-5862$.

51. Mellander, L. J.; Kurczy, M. E.; Najafinobar, N.; Dunevall, J.; Ewing, A. G.; Cans, A.-S. Sci. Rep. $2014,4,3847$. 
52. Jimenez-Valdes, R. J.; Rodriguez-Moncayo, R.; Cedillo-Alcantar, D. F.; Garcia-Cordero, J. L. Anal. Chem. 2017, 89 (10), $5210-5220$.

53. Fu, K.; Kwon, S.-R.; Han, D.; Bohn, P. W. Acc. Chem. Res. 2020, 53 (4), 719-728.

54. Karimian, N.; Ugo, P. Curr. Opin. Electrochem. 2019, 16, 106-116.

55. Fan, Y.; Han, C.; Zhang, B. Analyst 2016, 141 (19), 5474-5487.

56. Clausmeyer, J.; Schuhmann, W. TrAC. 2016, 79, 46-59.

57. Zhang, X.; Hatamie, A.; Ewing, A. G. Current Opinion in Electrochemistry 2020, 22, 94-101.

58. Hu, K.; Liu, Y.-L.; Oleinick, A.; Mirkin, M. V.; Huang, W.-H.; Amatore, C. Curr. Opin. Electrochem. 2020, 22, 44-50.

59. Cans, A. S.; Wittenberg, N.; Eves, D.; Karlsson, R.; Karlsson, A.; Orwar, O.; Ewing, A. Anal. Chem. 2003,75 (16), $4168-4175$.

60. Cans, A. S.; Wittenberg, N.; Karlsson, R.; Sombers, L.; Karlsson, M.; Orwar, O.; Ewing, A. Proc. Natl. Acad. Sci. U. S. A. 2003, 100 (2), $400-404$.

61. Bedioui, F.; Griveau, S. Electroanalysis 2013, 25 (3), 587-600.

62. Calas-Blanchard, C.; Catanante, G.; Noguer, T. Electroanalysis 2014, 26 (6), 1277-1286.

63. Gulaboski, R.; Mirceski, V.; Kappl, R.; Hoth, M.; Bozem, M. J. Electrochem. Soc. 2019, 166 (8), G82-G101.

64. Ben-Amor, S.; Vanhove, E.; Belaidi, F. S.; Charlot, S.; Colin, D.; Rigoulet, M.; Devin, A.; Sojic, N.; Launay, J.; Temple-Boyer, P.; Arbault, S. Electrochim. Acta 2014, 126, 171-178.

65. Lefrancois, P.; Girard-Sahun, F.; Badets, V.; Clement, F.; Arbault, S. Electroanalysis 2021, 33 (4), $882-890$.

66. Jesorka, A.; Stepanyants, N.; Zhang, H.; Ortmen, B.; Hakonen, B.; Orwar, O. Nat. Protoc. 2011, 6 (6), $791-805$.

67. Amatore, C.; Arbault, S.; Bouton, C.; Coffi, K.; Drapier, J. C.; Ghandour, H.; Tong, Y. H. ChemBioChem 2006,7 (4), 653-661.

68. Amatore, C.; Arbault, S.; Bouret, Y.; Cauli, B.; Guille, M.; Rancillac, A.; Rossier, J. Chemphyschem 2006, 7 (1), $181-187$.

69. Malferrari, M.; Becconi, M.; Rapino, S. Anal. Bioanal. Chem. 2019, 411 (19), 4365-4374.

70. Badets, V.; Pandard, J.; Sojic, N.; Arbault, S. Chemelectrochem 2016, 3 (12), 2288-2296.

71. Marcu, R.; Rapino, S.; Trinei, M.; Valenti, G.; Marcaccio, M.; Pelicci, P. G.; Paolucci, F.; Giorgio, M. Bioelectrochem. $2012,85,21-28$.

72. Bard, A. J.; Faulkner, L. R. John Wiley \& Sons: New York, 2001.

73. Lefrancois, P.; Goudeau, B.; Arbault, S. Analyst 2021, 145 (24), 7922-7931.

74. Amatore, C.; Arbault, S.; Bouton, C.; Drapier, J.-C.; Ghandour, H.; Koh, A. C. W. ChemBioChem 2008, 9 (9), $1472-1480$. 